\title{
Clinical Outcome of Late Initiation of Antiviral Therapy in Patient with Negative COVID-19 PCR Test
}

\section{Mohammed M Al-Amri ${ }^{1 *}$, Wael F Alblowi ${ }^{2}$, Hassan Y Alghar ${ }^{2}$, Abdulmohsen H Almeffarej ${ }^{3}$ and Ala J Malhis ${ }^{4}$}

${ }^{1}$ Department of Internal Medicine, Medical Consultant at King Saud Medical City, Saudi Arabia

${ }^{2}$ Department of Internal Medicine, Medical Consultant, Allergist and Clinical Immunologist at King Saud Medical City, Saudi Arabia

${ }^{3}$ Department of Internal Medicine, Resident of internal Medicine at King Saud

Medical City, Saudi Arabia

${ }^{4}$ Pharmaceutical Care Department, Clinical Pharmacist King Saud Medical City,

Saudi Arabia

*Corresponding Author: Mohammed M Al-Amri, Department of Internal Medicine,

Medical Consultant at King Saud Medical City, Riyadh, Saudi Arabia.
Received: October 13, 2020

Published: November 10, 2020

(C) All rights are reserved by Mohammed $\mathbf{M}$

Al-Amri., et al.

\begin{abstract}
54 Years old Indian diabetic gentleman. Presented to emergency medicine department with one day of shortness of breath, cough and Right sided chest pain. Accompanied with 4 days history of fever, not documented. Patient was desating on Room air (54\% oxygen saturation) intubated by ER team. Chest X Ray revealed bilateral peripheral consolidation and patchy infiltrates bilaterally. CT of the chest showed Bilateral lung infiltrates and effusion Plus multi focal ground glass opacities. Patient was investigated for COVID 19, underwent total of 4 swabs. The first swab being probable for COVID 19 and the next 3 sample were negative for COVID 19. Treated with triple antiviral therapy (Ribavirin, Lopinavir/Ritonavir and Interferon beta1b), methylprednisolone and Ceftriaxone. Clinicians should be alert to the COVID 19 infection symptoms even with negative swab result.
\end{abstract}

Keywords: 2019-nCoV; COVID-19; COVID-19 Management; COVID-19 Treatment; Coronavirus; SARS; SARS-CoV-2

\section{Introduction}

Corona virus 2019 also known as severe acute respiratory syndrome coronavirus 2 (SARS-CoV-2). COVID-19 has been found to be the cause of severe pneumonia and acute respiratory distress syndrome (ARDS). We present a case of elderly male presenting with fever, cough, and shortness of breath, chest pain found to be negative swab result for COVID-19 and treated on IV corticosteroids, ceftriaxone and triple antiviral therapy Ribavirin, Lopinavir/ Ritonavir and Interferon beta1b [4].

\section{Case Presentation}

54 Years old Indian diabetic male. Presented to emergency medicine department with one day of shortness of breath, cough and right side chest pain. Accompanied with 4 days history of fever, not documented. Patient was desating in RA, $54 \%$, intubated by ER team and later admitted in ICU under care of medical personnel. In date of 15 June 2020. On initial physical assessment patient was conscious, disoriented. Afebrile temperature of 37.2. Vitals measurement BP 163/84, HR 128 bpm. With diminished breathing sounds and bilateral crackles on chest auscultation. Patient was put under mechanical ventilation and set of FiO2 100\% plus PEEP of 10. His initial investigations showed no leukocytosis (count of 9.1 $\mathrm{x} 10^{9}$ ). D- Dimer of $2.28 \mathrm{mg} / \mathrm{L}$. (Refer to table 1 for detailed laboratory results). Chest $\mathrm{X}$ Ray revealed bilateral peripheral consolidation and patchy infiltrates bilaterally (See figure 1). 


\begin{tabular}{|l|c|c|c|}
\hline Test & Value & Test & Value \\
\hline WBC & 9.1 & Creatinine & 139.48 \\
\hline HGB & 11.8 & Urea & 8.67 \\
\hline MCV & 89.1 & Sodium & 133.33 \\
\hline MCH & 29.9 & Potassium & 5.82 \\
\hline PLT & 229 & Chloride & 103.61 \\
\hline INR & 1.04 & ALT & 60.42 \\
\hline & & AST & 60.42 \\
\hline & & ALP & 70.33 \\
\hline Total Bilirubin & 6.9 & Albumin & 26.42 \\
\hline CK & 597 & LDH & 1288.90 \\
\hline
\end{tabular}

Table 1: Detailed investigations results on arrival in hospital.

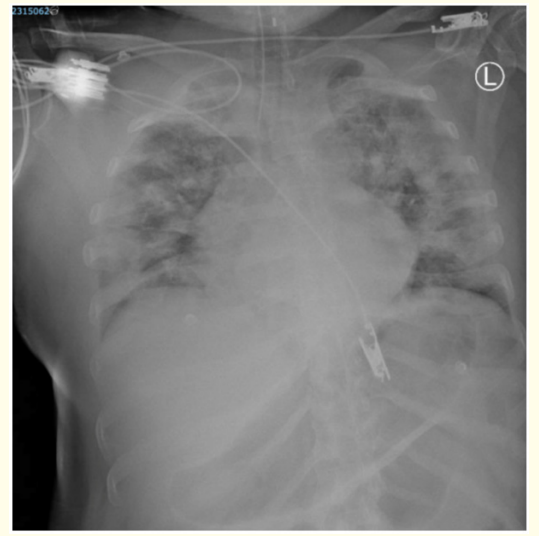

Figure 1: On presentation.

In hospital, patient stayed in ICU for almost 3 days for which he was extubated (17 June 2020); after reassessed for mechanical ventilation demand, in addition to improvement of chest X-ray dated 16/6 (See figure 2). In subsequent couple of days post extubation patient did showed stable clinical condition. But still he is requiring Oxygen from 3-4 L through nasal cannula. He was conscious and ambulating. In contrast, his lab investigations showed contrary picture (S.ferritin $2575 \mathrm{ng} / \mathrm{mL}$, CRP $238 \mathrm{mg} / \mathrm{L}$ and persistent positive D-Dimer $>1 \mathrm{mg} / \mathrm{L}$ ). Medical team decided to do CT spiral PE study and reported in 20 June 2020 to be negative for pulmonary embolism, while it revealed finding of Bilateral lung infiltrates and effusion Plus multi focal ground glass opacities in both sides, effusion being more in right side (Refer to figure 3). Patient was investigated for COVID 19, underwent total of 4 swabs. The first swab being probable, but not confirming (13 June 2020 "Before presenting to hospital") and the next 3 sample were negative for the infection COVID 19 dated (15 June, 17 June and 20 June of 2020). In 23 of June 2020, Medical team decided to treat patient as swab negative covid 19 respiratory infection. Started on triple antiviral therapy (Ribavirin, Lopinavir/Ritonavir and Interferon beta1b). methylprednisolone $40 \mathrm{mg}$ twice a day since admission and ceftriaxone.

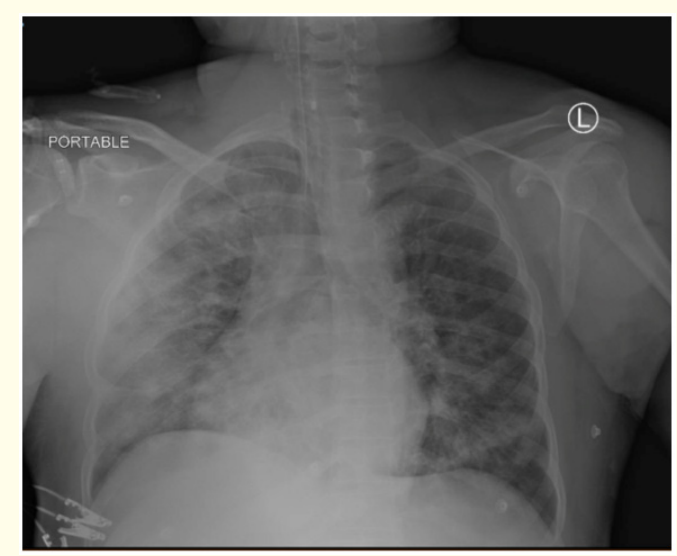

Figure 2: 2 days post admission.
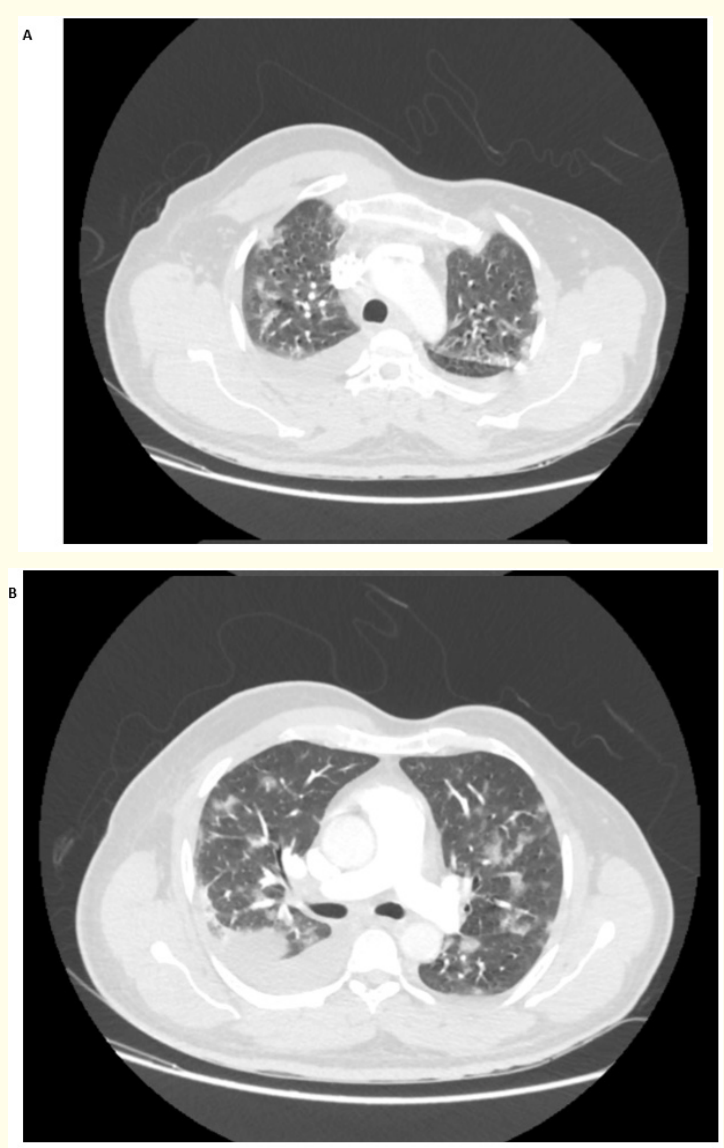


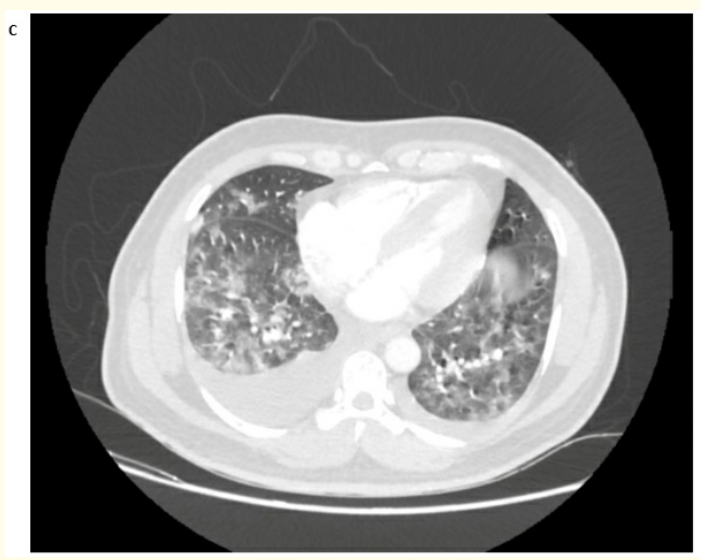

Figure 3: CT spiral study 20 of June 2020; with contrast. A) Apical view, showed some bronchial tractions. B) Pulmonary artery view, showing no filling defect. With patchy infiltrate and Rt pleural effusion. C) View at lower zones level, again demonstrating Rt pleural effusion and multi focal infiltrations + ground glass opacities. LV wall clearly hypertrophied.

\begin{tabular}{|l|c|c|c|}
\hline Test & Value & Test & Value \\
\hline WBC & 15.2 & Creatinine & 72.78 \\
\hline HGB & 13.2 & Urea & 8.86 \\
\hline MCV & 87.5 & Sodium & 137.55 \\
\hline MCH & 29.4 & Potassium & 3.64 \\
\hline PLT & 445 & Chloride & 101.73 \\
\hline INR & 1.11 & ALT & 195.47 \\
\hline PTT & 23.7 & AST & 71.89 \\
\hline Lymphocyte & 2.4 & ALP & 168.94 \\
\hline Total Bilirubin & 6.9 & Albumin & 30.07 \\
\hline
\end{tabular}

Table 2: Follow up investigations results in 21/6/2020.

\section{Results and Discussion}

In a similar study conducted by Hung IF., et al. in Hongkong, China, the median number of days from symptom onset to start of study treatment was 5 days. For the primary endpoint of time from start of study treatment to negative nasopharyngeal swab, the combination group had a significantly shorter median time of 7 days than the control group of 12 days [4]. Compared to our study. The triple therapy in our patient started after 7 days from developing symptoms. He presented with severe dyspnea, fever, cough and radiologically with Bilateral lung infiltrates and effusion Plus multi focal ground glass opacities in spiral CT. A trial of triple antiviral therapy (Ribavirin, Lopinavir/Ritonavir and Interferon beta1b) started. After two days of thereby. He was no longer require oxygen thereby and was discharged home. In contrast to Ivan's study, our study shows clinical improvement and shorter duration of hospital stay. Therefore, a delayed presentation shouldn't abstain from starting triple anti-viral therapy.

In another study Chen., et al. have reported a similar case in China with a patient admitted last January 2020 and found 3 negative results of SARS-CoV2 on three days 10,13 and 16. It has been showed in the study that the patient was having typical COVID-19 symptoms; high-grade fever and cough and showing a characteristic lab finding with leukopenia and lymphopenia [8]. This was also found in the case presented of this paper. Some previous studies showed that nasal swab is associated with increase rate of false negative results. For instance, Chaojun Xie., et al. have traced 166 patients with respiratory symptoms discharged with negative COVID-19 nasal swab nucleic acid test and discovered that $13.66 \%$ of them retested again and found to be positive of COVID-19. Additionally, 22 of these patients returned back as COVID-19 positive pneumonia. Chaojun Xie., et al. reported a median time of days from onset of symptoms to positive swab to be 26 days and from discharge to positive swab to be 7.5 days [6]. This contrasts with the current study where the patient was admitted for around 10 - 14 days. In another study, a nucleic acid testing for COVID-19 become positive in $5^{\text {th }}$ day of admission, but after repeating the test for the fifth time, which emphasizes the false negativity of the test initial attempts [5]. Repeated false negative nucleic acid test was supported by a study in the was conducted in December 2019 by Xingzhi Xie., et al. which illustrate confirming COVID-19 pneumonia in patients with initial false negative testing, necessitating putting CT chest as a standard in diagnosing COVID-19 infection [7].

\section{Conclusion}

In conclusion, SARS-CoV-2 is a novel and highly contagious virus, it is a serious infection that has led to thousands of cases of severe pneumonia, ARDS, and even deaths across the globe. This case reminds clinician that a patient with high clinical suspicion of COVID-19 but multiple negative swabs result should be continue isolation. Starting anti-viral triple thereby in mild to moderate covid 19 cases could have potential therapeutic effect even after 7 days of the symptom's appearance. 


\section{Bibliography}

1. Wang Lisheng., et al. "Review of the 2019 novel coronavirus (SARS-CoV-2) based on current evidence". International Journal of Antimicrobial Agents 55.6 (2020): 106-137.

2. Saudi Arabia's Ministry of Health, MOH Publications, COVID-19 Guidelines.

3. Centers for Disease Control and Prevention, National Center for Emerging and Zoonotic Infectious Diseases (NCEZID), Division of Healthcare Quality Promotion (DHQP).

4. Hung Fan-Nagi., et al. "Triple combination of interferon beta-1b, lopinavir-ritonavir, and ribavirin in the treatment of patients admitted to hospital with COVID-19: an open-label, randomised, phase 2 trial". The Lancet 395.10238 (2020): 1695-1704.

5. Feng, Hao., et al. "A case report of COVID-19 with false negative RT-PCR test: necessity of chest CT". Japanese Journal of Radiology 38.5 (2020): 409-410.

6. Xie Chaojun., et al. "False negative rate of COVID-19 is eliminated by using nasal swab test". Travel Medicine and Infectious Disease 37 (2020).

7. Xie Xingzhi., et al. "Chest CT for Typical Coronavirus Disease 2019 (COVID- 19) Pneumonia: Relationship to Negative RTPCR Testing". Radiology 269.2 (2020): 41-45.

8. Chen Li-Da., et al. "A COVID-19 patient with multiple negative results for PCR assays outside Wuhan, China: a case report". BMC Infectious Diseases 20.517 (2020): 1-4.

\section{Assets from publication with us}

- Prompt Acknowledgement after receiving the article

- Thorough Double blinded peer review

- Rapid Publication

- Issue of Publication Certificate

- High visibility of your Published work

Website: www.actascientific.com/

Submit Article: www.actascientific.com/submission.php

Email us: editor@actascientific.com

Contact us: +919182824667 